\title{
Residues of organochlorine pesticides in surface soils from college school yards in Beijing, China
}

\author{
WANG Xiaofei ${ }^{1}$, WANG Dianzhong ${ }^{2}$, QIN Xiaofei ${ }^{1}$, XU Xiaobai $^{1, *}$ \\ 1. State Key Laboratory of Environmental Chemistry and Ecotoxicology, Research Center for Eco-Environmental Sciences, Chinese Academy of \\ Sciences, Beijing 100085, China. E-mail: wangxf116@ gmail.com \\ 2. State Key Laboratory of Remote Sensing Science, Institute of Remote Sensing Applications, Chinese Academy of Sciences, Beijing 100101, China
}

Received 7 November 2007; revised 3 January 2008; accepted 15 January 2008

\begin{abstract}
Organochlorine pesticides (OCPs) have been a major environmental issue, attracting much scientific concern because of their nature of toxicity, persistence, and endocrine disrupting effects. Soil samples were collected from ten college school yards in Beijing in 2006 and analyzed to determine fifteen OCPs. Dichlorodiphenyltrichloroethanes (DDTs) were found to be the main pollutants, accounting for $93.70 \%$ of total OCPs, followed by hexachlorohexanes ( $\mathrm{HCHs})(2.25 \%)$ and hexachlorobenzene $(\mathrm{HCB})(1.82 \%)$. Content of chlordanes (CHLs), heptachlors (HEPTs), and endosulfans comprised $0.51 \%, 1.05 \%$, and $0.79 \%$ of fifteen OCPs, respectively. The preliminary pollution assessment indicated that DDTs have caused high OCPs levels in some schools. Source identification showed that HCHs in soils were originated from an old mixed source of technical HCHs and lindane. And DDTs were mainly from mixed use of technical DDTs and dicofol containing DDT impurities. According to GB15618-1995 (guidelines of Chinese environmental quality standards for soils), HCHs and DDTs levels might be categorized as little and low polluting pesticides. This study indicated that the environmental quality of college school yards with large green land were not as good as was expected and there existed potential exposure risk of college population to OCPs.
\end{abstract}

Key words: organochlorine pesticides (OCPs); pollution; soil; college school yards

\section{Introduction}

Health risks in urban environment, especially in megacities are an ongoing concern. The fast population growth and urbanization might exacerbate these risks, as accelerated growth has lead to increased exposures to a variety of toxic chemicals and other health hazards. Urban soils, especially those in residential areas and parks provide a direct contact pathway for toxic chemicals towards human bodies (Mielke et al., 1999; Madrid et al., 2002; Chen et al., 2005; Li et al., 2001).

Beijing, the capital of China, is the main cultural center. As the cradle of modern education of China, Beijing has more than 150 colleges so far. Because of the long history and reputation as good education establishments, colleges in Beijing attract more than 0.3 million college students from all over China every year. Since most school yards have large amounts of green land, college school yards thus become leisure site for students and residents nearby. However, a questionnaire about the environmental quality of college school yards showed that various sorts of chemicals were applied 3-4 times a year for the purpose of protecting vegetations in all of the investigated colleges. Among these chemicals, some banned pesticides like

\footnotetext{
* Corresponding author. E-mail: xuxb@rcees.ac.cn.
}

methamidophos were still in use. This implies that there are potential exposure risks for young students and residents nearby. Organochlorine pesticides (OCPs) attracted wide concern for decades because of their nature of persistence, biomagnification, and high toxicity to nontarget organisms (Dimond and Owen, 1996; Nakata et al., 2002). Some of OCPs are even identified as endocrine disrupting pesticides by USEPA (1998). OCPs were well documented in urban and suburban soils of Beijing (Ma et al., 2003; Zhu et al., 2005, Zhang et al., 2005; Li et al., 2006, 2008), but few researches have ever been conducted on soils in college school yards.

The present study was conducted to (1) estimate OCPs levels in college schools, (2) to identify the sources of the detected OCPs, and (3) to evaluate the potential risks to human health and environmental safety in college school yards.

\section{Materials and methods}

\subsection{Materials and reagents}

A mixed stock standard solution of OCPs containing $\alpha$-hexachlorohexanes $(\mathrm{HCH}), \beta-\mathrm{HCH}, \gamma-\mathrm{HCH}, \delta-\mathrm{HCH}$, heptachlor (HEPT), heptachlor epoxide (HEPX), transchlordane (TC), cis-chlordane (CC), $\alpha$-endosulfan, 
$\beta$-endosulfan, $\quad p, p^{\prime}$-di-chlorodiphenyldichloroethylene (DDE), $p, p^{\prime}$-di- chlorodiphenyldichloroethane (DDD), and $p, p^{\prime}$-dichlorodiphenyltrichloroethanes (DDT) each at a concentration of $1,000 \mu \mathrm{g} / \mathrm{ml}$ was obtained from Chem Service (West Chester, USA). The $o, p^{\prime}$-DDT standard solution of $100 \mathrm{mg} / \mathrm{L}$ was purchased from National Research Center for Certified Reference Materials of China. Hexachlorobenzene (HCB) and 2,4,5,6-tetrachloro-mxylene (TCMX, the surrogate) was bought from Supelco (Bellfonte, USA). The working standards were prepared with isooctane. Florisil (Dikma Co., USA) was activated at $600^{\circ} \mathrm{C}$ for $6 \mathrm{~h}$, and then at $130^{\circ} \mathrm{C}$ for $16 \mathrm{~h}$. Hexane and ethyl ether (Dikma, USA) used were of pesticide grade. Acetone (Beijing Chemical Factory, China) was of analytical grade and redistilled in all-glass system prior to use.

\subsection{Sample collection}

Ten college school yards in Beijing, China, were selected as the study area (Fig.1), including ST (Research Center for Eco-Environmental Sciences, Chinese Academy of Sciences), ND (China Agricultural University), NJ (Chinese Academy of Agricultural Mechanization Science), SW (Institute of Biophysics, Chinese Academy of Sciences), BL (Beijing Forestry University), BYY (Beijing Language and Culture University), DZ (China University of Geoscience), BK (University of Science and Technology Beijing), BH (Beihang University), and BY (Peking University Health Science Center). The surface soils $(0-20 \mathrm{~cm})$ were collected. Each composite sample was constituted by 15-20 sub-samples in the same school yard. The samples were freeze dried with a Freeze Dryer (Yamato, Japan), ground, and sieved through a 40-mesh and stored at $-18^{\circ} \mathrm{C}$ until analysis.

\subsection{Sample extraction and cleanup}

After $1 \mathrm{ml}$ of TCMX $(100 \mathrm{ng} / \mathrm{ml})$ was added as surrogate

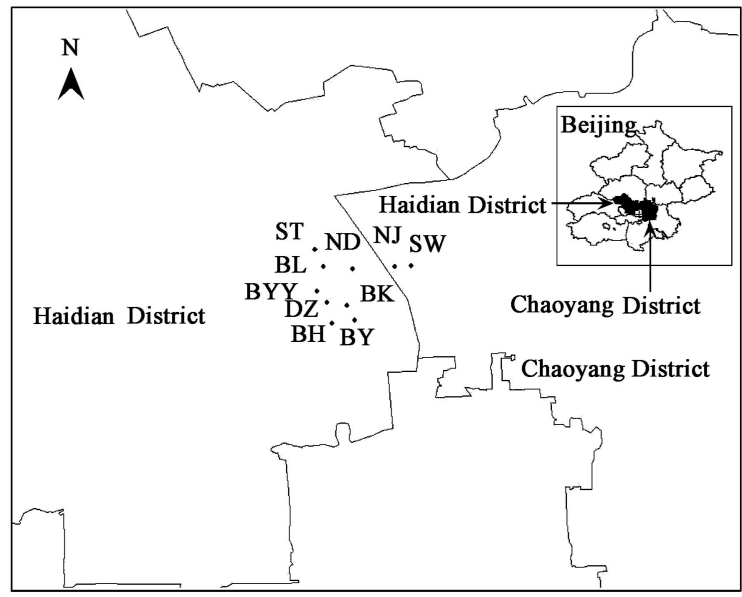

Fig. 1 Map of sampling sites. ST: Research Center for EcoEnvironmental Sciences, Chinese Academy of Sciences; ND: China Agricultural University; NJ: Chines Academy of Agricultural Mechanization Science; SW: Institute of Biophysics, Chinese Academy of Sciences; BL: Beijing Forestry University; BYY: Beijing Language and Culture University; DZ: China University of Geoscience; BK University of Science and Technology Beijing; BH: Beihang University; BY: Peking University Health Science Center. and $5 \mathrm{~g}$ active $\mathrm{Cu}$ was added to eliminate element sulfur, 5 g soil was ultrasonically extracted in $30 \mathrm{ml}$ acetone/hexane (1:1) for $3 \mathrm{~min}$ and centrifuged for separation. The process was repeated three times. Then the solvent was combined and rotary evaporated at vacuum, and then, reduced to 1 $\mathrm{ml}$ at gentle stream of nitrogen. The concentrated extract was further cleaned up with a Florisil column $(30 \mathrm{~cm} \times$ $10 \mathrm{~mm}$ i.d.) packed with $5 \mathrm{~g}$ florisil. After the sample was transferred into the column, it was then eluted with $40 \mathrm{ml}$ hexane/ethyl ether $(7: 1, V / V)$. The elute was concentrated in a rotary vacuum evaporator and reduced to $0.1 \mathrm{ml}$ by a gentle nitrogen stream for determination.

\subsection{OCPs determination}

The determination of OCPs was performed with Agilent $6890 \mathrm{GC}-\mu \mathrm{ECD}$ (USA) equipped with a fused silica capillary DB-5 column (Agilent, USA, $30 \mathrm{~m} \times 0.25 \mathrm{~mm}$ i.d., $0.25 \mu \mathrm{m}$ film thickness). Nitrogen was used as both carrier and makeup gas. Inlet and detector temperature were 225 and $310^{\circ} \mathrm{C}$, respectively. The oven temperature program was as follows: initial temperature $100^{\circ} \mathrm{C}$ held for $2 \mathrm{~min}$, increased to $160^{\circ} \mathrm{C}$ at $10^{\circ} \mathrm{C} / \mathrm{min}$, then, to $230^{\circ} \mathrm{C}$ at $4^{\circ} \mathrm{C} / \mathrm{min}$, and to $280^{\circ} \mathrm{C}$ at $10^{\circ} \mathrm{C} / \mathrm{min}$, held for 10 min. One micro liter of each sample was injected in the splitless mode. Identification of the compounds was based on the retention time with corresponding standards and confirmed on an Agilent 6890GC equipped with a 5973 mass selective detector (MSD) (USA). The quantification of the analytes was performed by comparison to external standard.

The limits of detection (LODs) were calculated with a signal to noise ratio of 3:1 in blank sample $(n=5)$. Detection limits varied for different OCPs and ranged from 0.012 to $0.095 \mathrm{ng} / \mathrm{g}$. The recoveries of OCPs spiked in matrix were in the range of $75 \%-115 \%$ and relative standard deviation (RSD) $(n=5)$ was $4 \%-12 \%$. The recoveries of surrogate (TCMX) spiked in blank, matrix, and samples were between $84 \%$ and $109 \%$.

\subsection{Data analysis}

Conventional statistical analyses and principal component analysis (PCA) were carried out using SPSS 13.0.

\section{Results and discussion}

\subsection{OCPs concentration}

Overall, concentrations of OCPs (sum of 15 OCPs) in soil ranged from 21.25 to $276.45 \mathrm{ng} / \mathrm{g}$ with standard deviation (SD) of $76.81 \mathrm{ng} / \mathrm{g}$. The highest concentration was detected in site BK while the lowest value was found in site ST. Average concentration of individual OCPs varied from $0.23 \mathrm{ng} / \mathrm{g}$ for $\alpha-\mathrm{HCH}$ to $42.38 \mathrm{ng} / \mathrm{g}$ for $o, p^{\prime}$ DDT (Table 1). Total $\mathrm{HCH}$ content (equivalent sum of $\alpha-, \beta-, \gamma-, \delta-\mathrm{HCH})$ was $2.25 \mathrm{ng} / \mathrm{g}$ accounting for $2.25 \%$ of $\sum$ OCPs while DDTs concentration ( $p, p^{\prime}$-DDE, $p, p^{\prime}$ DDD, $o, p^{\prime}$-DDT, $p, p^{\prime}$-DDT) was $93.68 \mathrm{ng} / \mathrm{g}$ comprising $93.70 \%$ of $\sum$ OCPs. Contents of HCB, CHLs (TC and $\mathrm{CC})$, HEPTs (HEPT and HEPX), and endosulfans $(\alpha-$ 
Table 1 Organochlorine pesticides (OCPs) analyzed

\begin{tabular}{|c|c|c|c|c|c|}
\hline Compounds & $\begin{array}{l}\text { Molecular } \\
\text { weight }\end{array}$ & $\begin{array}{l}\text { Mean } \\
(\mathrm{ng} / \mathrm{g})\end{array}$ & $\begin{array}{l}\text { Median } \\
(\mathrm{ng} / \mathrm{g})\end{array}$ & $\begin{array}{l}\text { Geometric } \\
\text { mean }(\mathrm{ng} / \mathrm{g})\end{array}$ & $\begin{array}{l}\text { Standard deviation } \\
(\mathrm{ng} / \mathrm{g})\end{array}$ \\
\hline$\alpha-\mathrm{HCH}$ & 291 & 0.23 & 0.23 & 0.19 & 0.12 \\
\hline $\mathrm{HCB}$ & 284.79 & 1.78 & 1.41 & 1.17 & 1.50 \\
\hline$\beta-\mathrm{HCH}$ & 291 & 1.15 & 1.06 & 0.77 & 0.71 \\
\hline$\gamma-\mathrm{HCH}$ & 291 & 0.39 & 0.36 & 0.33 & 0.24 \\
\hline$\delta-\mathrm{HCH}$ & 291 & 0.48 & 0.33 & 0.31 & 0.44 \\
\hline HEPT & 373.5 & 0.14 & 0.12 & 0.11 & 0.11 \\
\hline HEPX & 389.2 & 0.93 & 0.43 & 0.40 & 1.36 \\
\hline $\mathrm{TC}$ & 409.8 & 0.38 & 0.38 & 0.20 & 0.29 \\
\hline$\alpha$-Endosulfan & 406.9 & 0.31 & 0.09 & 0.11 & 0.59 \\
\hline $\mathrm{CC}$ & 409.8 & 0.13 & 0.10 & 0.09 & 0.14 \\
\hline$p, p^{\prime}-\mathrm{DDE}$ & 318 & 27.29 & 20.17 & 11.97 & 25.83 \\
\hline$\beta$-Endosulfan & 406.9 & 0.48 & 0.35 & 0.34 & 0.40 \\
\hline$p, p^{\prime}-\mathrm{DDD}$ & 320 & 6.47 & 3.22 & 3.60 & 7.51 \\
\hline$o, p^{\prime}-\mathrm{DDT}$ & 354.5 & 42.38 & 19.10 & 16.03 & 51.95 \\
\hline$p, p^{\prime}$-DDT & 354.5 & 17.54 & 7.67 & 4.34 & 30.09 \\
\hline$\sum \mathrm{HCHs}$ & & 2.25 & 2.10 & 1.77 & 1.19 \\
\hline $\bar{\sum} \mathrm{DDTs}$ & & 93.68 & 69.66 & 66.17 & 76.49 \\
\hline$\sum \mathrm{CHLs}$ & & 0.51 & 0.51 & 0.39 & 0.27 \\
\hline$\sum$ HEPTs & & 1.05 & 0.56 & 0.64 & 1.32 \\
\hline$\sum$ Endosulfans & & 0.79 & 0.60 & 0.56 & 0.67 \\
\hline$\sum \mathrm{OCPs}$ & & 99.98 & 77.48 & 74.45 & 76.81 \\
\hline
\end{tabular}

endosulfan and $\beta$-endosulfan ) were 1.78, 0.51, 1.05, and $0.79 \mathrm{ng} / \mathrm{g}$, comprising $1.82 \%, 0.51 \%, 1.05 \%$, and $0.79 \%$ of $\sum$ OCPs, respectively. Correlation analysis between OCPs showed only $p, p^{\prime}$-DDE, $p, p^{\prime}$-DDD, and $o, p^{\prime}$-DDT which correlated significantly with $\sum$ OCPs, and other OCPs did not have the relationship.

\subsection{Component analysis}

\subsubsection{HCHs}

Technical $\mathrm{HCH}$ is a mixture of $60 \%-70 \% \alpha-\mathrm{HCH}, 2 \%-$ $12 \% \beta-\mathrm{HCH}, 10 \%-15 \% \gamma-\mathrm{HCH}$, and other minor isomers (Iwata et al., 1993). Its usage was banned in China in the mid 1980s. Afterwards, it was substituted by pure $\gamma-\mathrm{HCH}$ isomer (lindane), used about 3,200 tons in China (Li et al., 2001).

Concentration of $\sum \mathrm{HCHs}(\alpha-, \beta-, \gamma-$, and $\delta-)$ was in the range of $0.40-3.72 \mathrm{ng} / \mathrm{g}$ with $2.25 \mathrm{ng} / \mathrm{g}$ as average. The highest and lowest concentration was found in BY and $\mathrm{NJ}$, respectively. Soil contents of $\mathrm{HCH}$ reported elsewhere were listed in Table 2. Compared with previous study of Beijing, HCHs content in present study $(2.25 \mathrm{ng} / \mathrm{g})$ was found to be about 5 times lower than soils from 25 urban parks (10.54 ng/g) (Li et al., 2008) and soils from suburban areas of Beijing (10.35 ng/g) through systematic grid sampling. However, the median value $(2.10 \mathrm{ng} / \mathrm{g})$ was relatively higher than that in soil from Guanting Reservoir $(0.56 \mathrm{ng} / \mathrm{g})$ in exurb of Beijing (Zhang et al., 2005). In comparisons with other areas of China, the mean value was about 2.5-3 times lower than that in soils from grass land $(6.32 \pm 1.52 \mathrm{ng} / \mathrm{g})$ and wood land of Hong Kong (5.72 \pm $1.18 \mathrm{ng} / \mathrm{g}$ ) (Zhang et al., 2006), 10 times lower than that in soils from tree land $(20.94 \pm 12.4 \mathrm{ng} / \mathrm{g})$ in Taihu Lake area (Wang et al., 2007), and about 20 times lower than that in urban and rural soils (45.8 ng/g) from Tianjin (Gong et al., 2004a). Compared with urban soils from abroad, the levels (0.40-3.72 ng/g) were also low (e.g., soils from urban/industrial areas of Poland range between 0.36 and $110 \mathrm{ng} / \mathrm{g}$ (Falandysz et al., 2001) and the 0.6-6.6 ng/g for wood land of Austria (Weiss et al., 1998)). However, the levels were much higher than that in mountain soils from Teide $(0.11 \mathrm{ng} / \mathrm{g})$, Tenerife island in subtropical Atlantic (Ribes and Grimalt, 2002). Considering Beijing which is located in the temperate zone where pollutants can not easily evaporate from soil, the HCHs levels in soils from college school yards in Beijing could be categorized as slight pollution. Besides, the level was close to $\mathrm{HCH}$ in YMS (1.263 ng/g), a scenic site in exurb of Beijing (Li et

Table 2 Comparison of HCHs and DDTs in soils from other regions

\begin{tabular}{|c|c|c|c|c|}
\hline Area & Land use & $\sum \mathrm{HCHs}(\mathrm{ng} / \mathrm{g})$ & $\sum$ DDTs (ng/g) & Refercence \\
\hline Costa Rica & Soils not used with OCPs & 0.07 (sum of $\alpha-, \gamma-\mathrm{HCH})$ & 0.22 (sum of $p, p^{\prime}$-DDE, DDD) & Daly et al., 2007 \\
\hline Teide, Tnerife Island & Mountain soils & 0.11 (sum of $\alpha-, \gamma-, \delta-\mathrm{HCH})$ & $5.4\left(\right.$ sum of $\left.p, p^{\prime}-\mathrm{DDE}, \mathrm{DDT}\right)$ & Ribes and Grimalt, 2002 \\
\hline Katowice, Poland & Urban and suburban soil & $5.9 \pm 3.3$ & $110 \pm 89$ & Falandysz et al., 2001 \\
\hline Hong Kong, China & Grass land and wood land & $6.32 \pm 1.52,5.72 \pm 1.18$ & $0.24 \pm 0.20,0.32 \pm 0.20$ & Zhang et al., 2006 \\
\hline Tianjin, China & Urban and rural soil & 45.8 & $50.5 \pm 129.1$ & Gong et al., 2004a, 2004b \\
\hline Nantong, China & Cotton field topsoil & & $183.07 \pm 171.68$ & Yang et al., 2008 \\
\hline Beijing, China & Park soil & 10.54 & 162.0 & Li et al., 2008 \\
\hline Beijing, China & Scenic soil in exurb (YMS) & 1.26 & 0.62 & Li et al., 2008 \\
\hline Beijing, China & Soils from Guanting Reservoir & n.d. $-8.96,0.56$ (median) & n.d.-94.07, 5.11(median) & Zhang et al., 2005 \\
\hline Taihu Lake, China & Tree land surface soil & $20.94 \pm 12.4$ & $81.62 \pm 46.34$ & Wang et al., 2007 \\
\hline Beijing, China & Suburban subsurface soil & 10.35 & 140.79 & Zhu et al., 2005 \\
\hline
\end{tabular}

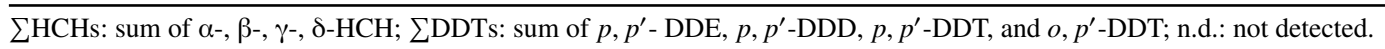


al., 2008).

Among the four isomers, content of $\beta-\mathrm{HCH}$ in most of samples was the highest among the four isomers and comprised $8.0 \%-91.67 \%$ (51.11\% as average) of $\sum \mathrm{HCHs}$. Compared with the portion of $\beta-\mathrm{HCH}$ in technical $\mathrm{HCH}$ (2\%-12\%, Iwata et al., 1993), the high values in most of samples indicate that there was little new input of $\mathrm{HCH}$ in research areas.

The ratio of $\alpha-\mathrm{HCH} / \gamma-\mathrm{HCH}$ is ranging from 4 to 7 for technical $\mathrm{HCH}$ and close to zero for lindane (Karlsson et al., 2000). Thus, the ratio was widely used to determine whether $\mathrm{HCH}$ was from technical $\mathrm{HCH}$ or lindane. The $\alpha-\mathrm{HCH} / \gamma-\mathrm{HCH}$ ratio in this study ranges from 0.26 to 1.08, suggesting the mixed sources of technical $\mathrm{HCH}$ and lindane. This result was consistent with $\mathrm{HCH}$ sources on pine needles, particulate matters, and soils from urban parks in Beijing (Xu et al., 2004, 2005; Li et al., 2008).

\subsubsection{DDT}

Although it was banned in agricultural use in China in 1980s, DDT related substances can still be detected in water, air, soils, and biota (Wu et al., 2005; Xu et al., 2005; Xue et al., 2006).

DDTs compounds were in range of $0.42-76.77 \mathrm{ng} / \mathrm{g}$ for $p, p^{\prime}$-DDE, 0.67-26.59 ng/g for $p, p^{\prime}$-DDD, 0.80-163.90 $\mathrm{ng} / \mathrm{g}$ for $o, p^{\prime}$-DDT, and $0.31-104.58 \mathrm{ng} / \mathrm{g}$ for $p, p^{\prime}$-DDT. DDTs thus shows the largest concentration range among the measured OCPs.

Levels of DDTs in soils reported in other regions were listed in Table 2. Average DDT value $(93.68 \mathrm{ng} / \mathrm{g}$ ) was much higher than residual levels in YMS $(0.62 \mathrm{ng} / \mathrm{g})(\mathrm{Li}$ et al., 2008), and that in Guanting Reservoir (ND-94.07 $\mathrm{ng} / \mathrm{g}, 5.11 \mathrm{ng} / \mathrm{g}$ as median). However, the levels were low compared with what was reported in soils from suburban (140.79 ng/g) and urban parks (162.0 ng/g) of Beijing. In contrast to other areas in China, DDT concentrations were higher than that in soils from tree land (81.62 \pm 46.34 $\mathrm{ng} / \mathrm{g}$ ) in Taihu Lake area (Wang et al., 2007). Furthermore, it was 300-400 times higher than DDT levels in soils from grass land $(0.24 \pm 0.20 \mathrm{ng} / \mathrm{g})$ and wood land $(0.32$ $\pm 0.20 \mathrm{ng} / \mathrm{g}$ ) of Hong Kong (Zhang et al., 2006). It is important to note that the DDTs levels in present study was about 2 times higher than those from soils in Tianjin, a city with DDT production of 2,500-3,500 tons/year. In comparison with levels in cotton field $(183.07 \pm 171.68$ $\mathrm{ng} / \mathrm{g}$ ) with heavy pesticide application in Nantong, DDT content in this study was low. In comparison with regions outside China, the levels were close to that in urban soils $(110 \pm 89 \mathrm{ng} / \mathrm{g})$ from Katowice, Poland (Falandysz et al., 2001) but was much higher than that in mountain soils $(5.4 \mathrm{ng} / \mathrm{g})$ from Teide in subtropical Atlantic (Ribes and Grimalt, 2002) and soils not used with DDTs in Costa Rica (Daly et al., 2007). From what is discussed above, the DDT contamination should be a serious problem in Beijing's college school yards.

Technical DDT is typically composed of $77.1 \% p, p^{\prime}$ DDT, $14.9 \% o, p^{\prime}$-DDT, $4 \% p, p^{\prime}$-DDE, and some other trace impurities (Zhu et al., 2005). In the present study, content of $o, p^{\prime}$-DDT (42.38 ng/g as average ) was much more than other DDT compounds and accounted for $45.24 \%$ of $\sum$ DDTs (Table 1). Besides, the mean percentage of individual compounds in soils from college school yards were as follows: $o, p^{\prime}$-DDT $>p, p^{\prime}$-DDE $>$ $p, p^{\prime}$-DDT $>p, p^{\prime}$-DDD, which was different from the order of $p, p^{\prime}$-DDE $>p, p^{\prime}$-DDT $>p, p^{\prime}$-DDD $>o, p^{\prime}$-DDT reported in soils from outskirt of Beijing via systematic grid sampling method (Zhu et al., 2005). This suggested new input could be existing. It was reported that $o, p^{\prime}$-DDT was present in technical dicofol as impurity (Qiu et al., 2004) and the high level of $o, p^{\prime}$-DDT in soils from college school yards could be the result of present use of dicofol in these sites.

DDE and DDD have no insecticidal use and they mainly come from DDT, thus, the ratio of $\left(p, p^{\prime}\right.$-DDE $+p, p^{\prime}$ DDD) $/ p, p^{\prime}$-DDT can be used as indicator of the "age" of DDT (Rapaprt and Eisenreich, 1986; Xu et al., 2005). The ratio more than 1 is generally expected for aged mixtures in the environment and less than 1 suggests recent usage of parent DDT (Jaga and Dharmani, 2003). The ratios of soils from college school yards were quite variable, ranging from 0.12 to 294.37 with 4.15 as geometric mean. Besides, the ratio was $>1$ in $70.0 \%$ samples, which denoted that the contamination by technical DDT occurred in the past in most of the sampling sites. However, about 30\% sampling sites had the ratio lower than 1 , which revealed new application of DDT existed in these colleges such as BY, ND, and ST.

Recently, the ratio of $o, p^{\prime}$-DDT/ $p, p^{\prime}$-DDT was applied to differentiate DDT contamination caused by technical DDT from that by dicofol use (Qiu et al., 2005). Since $o, p^{\prime}$-DDT is present in technical dicofol as impurity, relatively high value of the ratio indicates dicofol sources. Generally, the ratio ranges from 0.2 to 0.3 in technical DDT and 1.3 to 9.3 or higher in dicofol. In our study, the ratios varied from 0.02 to 312.64 with 3.69 as geometric mean, and exceed 0.3 in $80 \%$ samples, which reflected the important influence of dicofol. From what is discussed above, it could be concluded that usage of dicofol could be an important source of DDT in soils of college school yards.

\subsubsection{HCB}

HCB was mainly used for producing pentachlorophenol sodium and as pesticide on schistosome in oncomelania. It was also used on wood preservation. Although HCB was used in many applications in the past, there are no current commercial uses of HCB as an end product in China. It is now mainly the byproduct of some technochemicals and the impurity of some pesticide.

$\mathrm{HCB}$ was in range of $0.13-5.13 \mathrm{ng} / \mathrm{g}$ with $1.78 \mathrm{ng} / \mathrm{g}$ as average and accounted for $1.82 \%$ of total 15 OCPs (Table 1). The level was comparable with HCB detected in soils from fallow land of Taihu Lake area in China $(1.86 \pm 1.21 \mathrm{ng} / \mathrm{g})$ (Wang et al., 2007) and soils from Krakow, Poland (1.7-2.6 ng/g) (Falandysz et al., 2001). However, it was lower than soils from tree land (5.13 \pm $3.49 \mathrm{ng} / \mathrm{g})$, paddy field $(3.76 \pm 2.27 \mathrm{ng} / \mathrm{g})$ in Taihu Lake area (Wang et al., 2007), and urban soils from Katowice 
$(6.4 \pm 9.6 \mathrm{ng} / \mathrm{g})$ (Falandysz et al., 2001). Besides, HCB level was much higher than that in soils from wood land of Hong Kong $(0.03 \pm 0.02 \mathrm{ng} / \mathrm{g})$ (Zhang et al., 2006). The results indicate a low pollution level of $\mathrm{HCB}$ in soils from college school yards of Beijing. Although HCB has been prohibited from use as herbicides, wastes derived from chlorine related industries could be a possible HCB source to the environment.

\subsubsection{CHLs, HEPTs, and endosulfans}

CHLs (TC and CC), HEPTs (HEPT and HEPX), and endosulfans ( $\alpha$-endosulfan and $\beta$-endosulfan) accounted for $2.35 \%$ of total 15 OCPs (Table 1). They were also detected in the range of $0.03-0.88 \mathrm{ng} / \mathrm{g}, 0.16-4.84 \mathrm{ng} / \mathrm{g}$, and $0.14-2.41 \mathrm{ng} / \mathrm{g}$ for CHLs, HEPTs, and endosulfans, respectively. The average CHLs level $(0.51 \pm 0.27 \mathrm{ng} / \mathrm{g})$ was much higher than the levels in soils $(13.6 \mathrm{pg} / \mathrm{g})$ from Costa Rica (Daly et al., 2007) but comparable with that in soil $(0.46 \pm 0.53 \mathrm{ng} / \mathrm{g})$ from Krakow, Poland (Falandysz et al., 2001). Technical chlordane is generally used as insecticide, herbicide, and termiticide, and is still being used against termites in China with over 200 tons/year input recently ( $\mathrm{Xu}$ et al., 2005). The CHLs in soils of college school yards are likely to be associated with past pesticide use. The TC/CC ratio is generally used for understanding the emission history and degradability of chlordane. The ratio in technical chlordane mixture is 1.17 (Jantunen et al., 2000; Shen et al., 2005; Xu et al., 2005). TC is generally more volatile than CC, and if only volatility is considered, the ratio at $20^{\circ} \mathrm{C}$ would be expected to be 1.41 (Hinckley et al., 1990). The TC/CC value measured were in the range of $0.03-15.59$ (5.27 as mean), which were much higher than that in technical chlordane. This could be attributed to the concentration difference in soils. The significant difference of the ratios in this study also suggested that these compounds probably originated from different pollution sources.

HEPT was used primarily in termite, ant, and soil insect control in seed grains and metabolized to HEPX in soils. In present study, level of HEPX $(0.93 \mathrm{ng} / \mathrm{g})$ was much higher than that of HEPT $(0.14 \mathrm{ng} / \mathrm{g})$ (Table 1$)$, which indicated the historical use of HEPT in the study area. HEPT measured in our samples might be partly from the usage of commercial pesticides because it was one of the most widely used pesticides in China before 1983 .

\subsection{Principal component analysis (PCA)}

To get a further insight of the data, PCA was conducted for 6 groups of OCPs (HCHs, DDTs, HEPTs, CHLs, endosulfans, and HCB). Totally three factors (PC1, PC2, and PC3) were extracted and accounted for $72.58 \%$ of total variances. PC1 explained $30.10 \%$ of total variance and was associated with HCHs, HCB, and HEPTs. PC1, thus, substantially described HCHs and HCB since HEPTs accounted for only $0.79 \%$ of $\sum$ OCPs (Table 1). PC2 comprised $22.01 \%$ of the variance and associated with DDTs and CHLs. Endosulfans had moderate load on PC2 and PC3. According to their relevance to both PC1 and $\mathrm{PC} 2$, we can identify that $\mathrm{PC} 1$ and $\mathrm{PC} 2$ can be represented

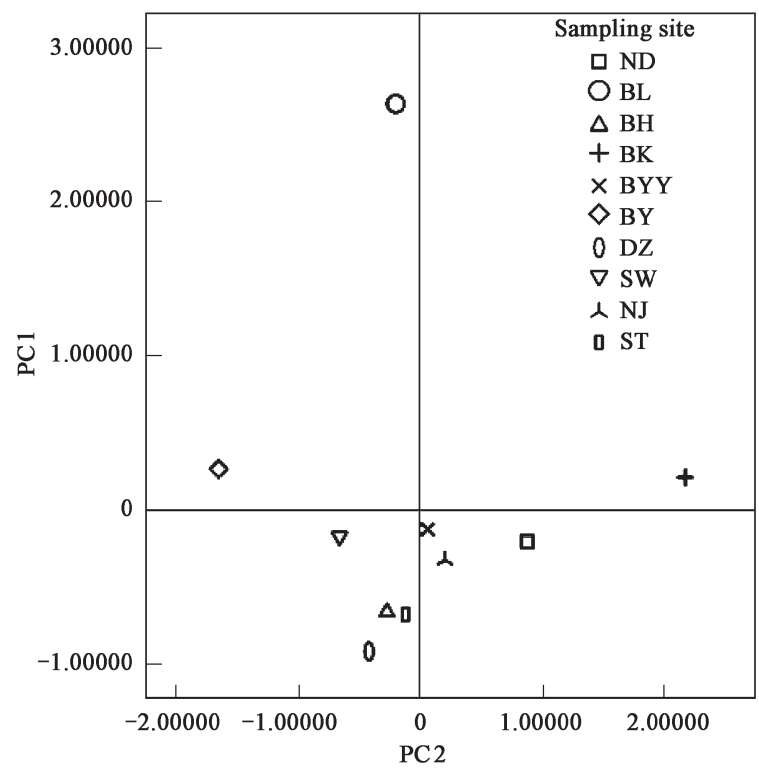

Fig. 2 Score plot of PC1 vs. PC2.

by HCHs and DDTs, respectively.

The sampling sites on PCA-score plot are shown in Fig. 2 with most of sites located near the origin. The results reflected relative low levels of OCPs in most of soil samples, as the origin represents the mean concentration of all samples. It was also indicated the mixed origin of both $\mathrm{HCH}$ and DDTs in these sampling sites. Two samples collected from site BK and BY could be observed with higher loads of PC2, indicating the DDTs influence on the two sites. And soil sample collected from BL had higher loads of PC1. The big difference in pollution type of these sampling sites could be associated with the difference in pesticide use.

\subsection{Pollution assessment}

On the basis of Chinese Environmental Quality Standard for Soils (GB15618-1995), the quality of soil was classified as having little pollution (below class I: below 50 $\mathrm{ng} / \mathrm{g}$ for both HCHs and DDTs), light pollution (between class I to class II: $50-500 \mathrm{ng} / \mathrm{g}$ ), moderate pollution (between class II and class III: $500-1,000 \mathrm{ng} / \mathrm{g}$ ), and heavy pollution (exceed class III: $>1,000 \mathrm{ng} / \mathrm{g}$ ). When consulted GB15618-1995, HCHs and DDTs levels of present study could be defined as having little pollution and slight pollution, respectively.

Considering that these OCPs might act as endocrine disruptors into account, this study indicates that soils from college school yards could serve as sources of OCPs exposure to college students. However, it is not clear from the present study as to what would be the impact on the biological availability of these OCPs to young college students in the study areas. With the fact that contaminants in soil would become less biologically available with time, the pesticide residue levels based on rigorous extraction and analysis might overestimate the risk to terrestrial organisms. EPA risk assessment guidelines assume that the soil ingestion rate for all individuals over age 7 to be $100 \mathrm{mg}$ soil/d and that soil DDT concentrations are $1 \mathrm{mg}$ 
DDT/kg soil (USEPA, 1989). We did not detect any OPCs at $\mathrm{mg} / \mathrm{kg}$ level, because all samples of this study were below permissible risk level. Further characterization such as availability of OCPs in soils might help in giving insight in to the potential exposure pathway for young populations in colleges.

\section{Conclusions}

This work revealed soil contamination information about 15 OCPs in college school yards of Beijing. HCHs and DDTs was the most abundant component, accounting for $95 \%$ of the total OCPs. On the basis of GB15618-1995, the HCHs could be classified as little pollution, whereas DDTs levels might be categorized as low pollution. However, considering their endocrine disrupting effect, there was potential exposure risk for college populations. $\mathrm{HCHs}$ were from old mixed sources of technical $\mathrm{HCH}$ and lindane in soils. For DDTs, past usage of technical DDTs was the main source. However, new input was also shown in about $30 \%$ samples. Dicofol also had an important contribution to soil DDTs in college school yards. These findings indicated the potential health risk of school yards. In addition, with the continuous application of relatively new pesticides like pyrethroids, unknown threat might be introduced. Therefore, we should think about whether the environmental quality of green lands is that perfect as we once thought in the past?

\section{Acknowledgments}

This work was supported by the National Basic Research Program (973) of China (No. 2003CB415005) and the National Natural Science Foundation of China (No. 20607026/B0702, 20437020).

\section{References}

Chen T B, Zheng Y M, Lei M, Huang Z C, Wu H T, Chen H et al., 2005. Assessment of heavy metal pollution in surface soils of urban parks in Beijing, China. Chemosphere, 60: 542-551.

Daly G L, Lei Y D, Teixeira C, Muir D C G, Castillo L E, Jantunen L M M, Wania F, 2007. Organochlorine pesticides in the soils and atmosphere of Costa Rica. Environ Sci Technol, 41: 1124-1130.

Dimond J B, Owen R B, 1996. Long-term residue of DDT compounds in forest soils in Maine. Environ Pollut, 92: $1122-1130$.

Falandysz J, Brudnowska B, Kawano M, Wakimoto T, 2001. Polychlorinated biphenyls and organochlorine pesticides in soils from the southern part of Poland. Arch Environ Contam Toxicol, 40: 173-178.

Gong Z M, Xu F L, Dawson R, Cao J, Liu W X, Li B G et al., 2004a. Residues of hexachlorocyclohexane isomers and their distribution characteristics in soils in the Tianjin area, China. Arch Environ Contam Toxicol, 46: 432-437.

Gong Z M, Tao S, Xu F L, Dawson R, Liu W X, Cui Y H et al., 2004b. Level and distribution of DDT in surface soils from Tianjin, China. Chemosphere, 54: 1247-1253.
Hinckley D A, Bidleman T F, Foreman W T, Tuschall J R, 1990. Determination of vapor pressures for nonpolar and semipolar organic compounds from gas chromatographic retention data. J Chem Eng Data, 35: 232-237.

Iwata H, Tanabe S, Sakai N, Tatsukawa R, 1993. Distribution of persistent organochlorines in the oceanic air and surface seawater and the role of ocean on their global transport and fate. Environ Sci Technol, 27: 1080-1098.

Jaga K, Dharmani C, 2003. Global surveillance of DDT and DDE levels in human tissues. Int J Occup Med Environ Health, 16: 7-20.

Jantunen L M M, Bidleman T F, Harner T, Parkhurst W J, 2000. Toxaphene, chlordane, and other organochlorine pesticides in Alabama air. Environ Sci Technol, 34: 5097-5105.

Karlsson H, Derek C, Muir G, Teixiera C F, Burniston D A, Strachan W M J et al., 2000. Persistent chlorinated pesticides in air, water and precipitation from the Lake Malawi Area, Southern Africa. Environ Sci Technol, 34: 4490-4495.

Li X H, Zhu Y F, Liu X F, Fu S, Xu X B, 2006. Distribution of $\mathrm{HCHs}$ and DDTs in soils from Beijing City, China. Arch Environ Contam Toxicol, 51: 329-336.

Li X H, Wang W, Wang J, Cao X L, Wang X F, Liu J C et al., 2008. Contamination of soils with organochlorine pesticidesin urban parks in Beijing, China. Chemosphere, 70: $1660-1668$.

Li Y F, Cai D J, Shan Z J, Zhu Z L, 2001. Gridded usage inventories of technical hexachlorocyclohexane and lindane for China with $1 / 6^{\circ}$ latitude by $1 / 4^{\circ}$ longitude resolution. Arch Environ Contam Toxicol, 41: 261-266.

Ma L L, Chu S G, Xu X B, 2003. Organic contamination in the greenhouse soils from Beijing suburbs, China. J Environ Monit, 5: 786-790.

Madrid L, Diaz-Barrientos E, Madrid F, 2002. Distribution of heavy metal contents of urban soils in parks of Seville. Chemosphere, 49: 1301-1308.

Mielke H W, Gonzales C R, Smith M K, Mielke P W, 1999. The urban environment and children's health: soils as an integrator of lead, zinc and cadmium in New Orleans, Louisiana, USA. Environ Res, 81: 117-129.

Nakata H, Kawazoe M, Arizono K, Abe S, Kitano T, Shimada H et al., 2002. Organochlorine pesticides and polychlorinated biphenyl residues in foodstuffs and human tissues from China: status of contamination, historical trend, and human dietary exposure. Arch Environ Contam Toxicol, 43: 473480.

Qiu X, Zhu T, Li J, Pan H, Li Q, Miao G, Gong J, 2004. Organochlorine pesticides in the air around the Taihu Lake, China. Environ Sci Technol, 38: 1368-1374.

Qiu X, Zhu T, Yao B, Hu J, Hu S, 2005. Contribution of dicofol to the current DDT pollution in China. Environ Sci Technol, 39: 4385-4390.

Rapaprt R A, Eisenreich S J, 1986. Atmospheric deposition of toxaphene to eastern north America derived from peat accumulation. Atmos Environ, 20: 2367-2379.

Ribes A, Grimalt J O, 2002. Temperature and organic matter dependence of the distribution of organochlorine compounds in mountain soils from the subtropical Atlantic (Teide, Tenerife island). Environ Sci Technol, 36: 1879-1885.

Shen L, Wania F, Lei Y D, Teixeira C, Muir D C G, Bidleman T F, 2005. Atmospheric distribution and long-rang transport behavior of organochlorine pesticides in North America. Environ Sci Technol, 39: 409-420.

USEPA, 1989. Risk assessment guidance for superfund, human 
health evaluation manual. Office of Emergency and Remedial Response, US Environmental Protection Agency (Doc No. EPA/540/1-89/002).

USEPA, 1998. Endocrine Disruptor Screening and Testing Advisor Committee (EDSTAC) Final Report.

Wang F, Jiang X, Bian Y R, Yao F X, Gao H J, Yu G F et al., 2007. Organochlorine pesticides in soils under different land usage in the Taihu Lake region, China. J Environ Sci, 19(5): 584-590.

Weiss P, Lorbeer G, Scharf S, 1998. Semivolatile organic compounds in spruce needles and forest soil of Austrian background forest sites. Organohalogen compounds, 39: 381-384.

Wu S P, Tao S, Zhang Z H, Lan T, Zuo Q, 2005. Distribution of particle-phase hydrocarbons, PAHs and OCPs in Tianjin, China. Atmos Environ, 39: 7420-7432.

Xu D D, Zhong W K, Deng L L, Chai Z, Mao X Y, 2004. Regional distribution of organochlorinated pesticide in pine needles and its indication for socioeconomic development. Chemosphere, 54: 743-752.
Xu D, Dan M, Song Y, Chai Z, Zhuang G, 2005. Concentration characteristics of extractable organohalogens in $\mathrm{PM}_{2.5}$ and $\mathrm{PM}_{10}$ in Beijing, China. Atmos Environ, 39: 4119-4128.

Xue N D, Zhang D R, Xu X B, 2006. Organochlorinated pesticide multiresidues in surface sediments from Beijing Guanting Reservoir. Water Res, 40: 183-194.

Yang X, Wang X, Bian Y, Chen F, Yu G, Gu C et al. 2008. Dicofol application resulted in high DDTs residue in cotton fields from northern Jiangsu Province, China. J Hazard Mater, 150: 92-98.

Zhang H B, Luo Y M, Zhao Q G, Wong M H, Zhang G L, 2006. Residues of organochlorine pesticides in Hong Kong soils. Chemosphere, 63: 633-641.

Zhang H, Lu Y L, Dawson R W, Shi Y J, Wang T Y, 2005. Classification and ordination of DDT and $\mathrm{HCH}$ in soil samples from the Guanting Reservoir, China. Chemosphere, 60: 762-769.

Zhu Y F, Liu H, Xi Z Q, Cheng H X, Xu X B, 2005. Organochlorine pesticides (DDTs and $\mathrm{HCHs}$ ) in soils from the outskirts of Beijing, China. Chemosphere, 60: 770-778. 